OPEN ACCESS

Edited by: Stylianos Kosmidis, Columbia University, United States

Reviewed by:

Tangui Maurice, INSERM U1198 Mécanismes Moléculaires dans les Démences Neurodégénératives, France Kei Cho,

King's College London, United Kingdom Victor Luna,

Columbia University Irving Medical Center, United States

*Correspondence:

Maria Vittoria Podda mariavittoria.podda@unicatt.it

Claudio Grassi

claudio.grassi@unicatt.it

Specialty section: This article was submitted to

Molecular Medicine,

a section of the journal

Frontiers in Cell and Developmental

Biology

Received: 09 April 2020

Accepted: 09 June 2020

Published: 03 July 2020

Citation:

Cocco S, Rinaudo M, Fusco S, Longo V, Gironi K, Renna P, Aceto G,

Mastrodonato A, Li Puma DD, Podda MV and Grassi C (2020)

Plasma BDNF Levels Following Transcranial Direct Current Stimulation Allow Prediction of Synaptic Plasticity and Memory Deficits in $3 \times T g-A D$ Mice. Front. Cell Dev. Biol. 8:541.

doi: 10.3389/fcell.2020.00541

\section{Plasma BDNF Levels Following Transcranial Direct Current Stimulation Allow Prediction of Synaptic Plasticity and Memory Deficits in 3xTg-AD Mice}

\author{
Sara Cocco' ${ }^{1}$ Marco Rinaudo ${ }^{1}$, Salvatore Fusco ${ }^{1,2}$, Valentina Longo ${ }^{1}$, Katia Gironi ${ }^{1}$ \\ Pietro Renna', Giuseppe Aceto' ${ }^{1}$, Alessia Mastrodonato', \\ Domenica Donatella Li Puma ${ }^{1,2}$, Maria Vittoria Podda ${ }^{1,2 *}$ and Claudio Grassi ${ }^{1,2 *}$
}

${ }^{1}$ Department of Neuroscience, Università Cattolica del Sacro Cuore, Rome, Italy, ${ }^{2}$ Fondazione Policlinico Universitario A. Gemelli IRCCS, Rome, Italy

Early diagnosis of Alzheimer's disease (AD) supposedly increases the effectiveness of therapeutic interventions. However, presently available diagnostic procedures are either invasive or require complex and expensive technologies, which cannot be applied at a larger scale to screen populations at risk of AD. We were looking for a biomarker allowing to unveil a dysfunction of molecular mechanisms, which underly synaptic plasticity and memory, before the $A D$ phenotype is manifested and investigated the effects of transcranial direct current stimulation (tDCS) in $3 \times \mathrm{Tg}-\mathrm{AD}$ mice, an experimental model of $A D$ which does not exhibit any long-term potentiation (LTP) and memory deficits at the age of 3 months $(3 \times T g-A D-3 M)$. Our results demonstrated that tDCS differentially affected $3 \times$ Tg-AD-3M and age-matched wild-type (WT) mice. While tDCS increased LTP at CA3-CA1 synapses and memory in WT mice, it failed to elicit these effects in 3xTg-AD-3M mice. Remarkably, $3 \times$ Tg-AD-3M mice did not show the tDCSdependent increases in pCREB $^{\text {Ser133 }}$ and pCaMKII ${ }^{\text {Thr286, }}$, which were found in WT mice. Of relevance, tDCS induced a significant increase of plasma BDNF levels in WT mice, which was not found in $3 \times \mathrm{Tg}-\mathrm{AD}-3 \mathrm{M}$ mice. Collectively, our results showed that plasticity mechanisms are resistant to tDCS effects in the pre-AD stage. In particular, the lack of BDNF responsiveness to tDCS in $3 \times \mathrm{Tg}-\mathrm{AD}-3 \mathrm{M}$ mice suggests that combining tDCS with dosages of plasma BDNF levels may provide an easy-to-detect and lowcost biomarker of covert impairment of synaptic plasticity mechanisms underlying memory, which could be clinically applicable. Testing proposed here might be useful to identify $A D$ in its preclinical stage, allowing timely and, hopefully, more effective disease-modifying interventions.

Keywords: Alzheimer's disease, blood biomarkers, BDNF, neuroplasticity, personalized medicine, tDCS 


\section{INTRODUCTION}

Alzheimer's disease $(\mathrm{AD})$ is a progressive neurodegenerative disorder responsible for the most common form of dementia. To date, therapeutic interventions against $\mathrm{AD}$ failed most likely because of late treatment initiation, i.e., when brain function and structure are already irreversibly damaged. Several lines of evidence suggest that pathogenic mechanisms of $\mathrm{AD}$ may affect the brain in the dark for many years owing to the brain's ability to cope with failures exploiting the so-called "cognitive reserve." Compensatory mechanisms can stave off neurodegeneration symptoms maintaining memory encoding for long time, and exhaustion of such brain ability may mark AD onset (Merlo et al., 2019). Thus, one primary goal is to detect preclinical AD, inasmuch as therapeutic interventions may have a higher success probability. Furthermore, some signs and symptoms, which manifested at early $\mathrm{AD}$ stages (e.g., depressive and cognitive symptoms in the measure of semantic memory and conceptual formation), are sometimes not recognized and/or mistaken for symptoms of other pathologies (Bature et al., 2017). This further stresses the need of reliable disease biomarkers, which may help early $\mathrm{AD}$ diagnosis.

Cognitive decline in $\mathrm{AD}$ is linked to pathological accumulation of amyloid-beta $(A \beta)$ and Tau proteins and their aggregation in brain regions which are essential for memory encoding and storage, such as the medial temporal lobe and related cortical areas (Serrano-Pozo et al., 2011; Bloom, 2014). Striking evidence from preclinical studies indicates that both $\mathrm{A} \beta$ and Tau have detrimental effects on molecular machinery of synapses, ultimately leading to decreased hippocampal long-term potentiation (LTP), a cellular correlate of memory (Irvine et al., 2008; Kopeikina et al., 2012; Ripoli et al., 2014; Fá et al., 2016; Puzzo et al., 2017; Gulisano et al., 2018a,b). However, decreased synaptic plasticity, similarly, to memory impairment, is manifested when the pathology has already developed. Molecular pathways, underlying synaptic plasticity, potentially deregulated or vulnerable in the pre-symptomatic stage, might provide early biomarkers to predict the onset and/or progression of the disease.

Recent studies, including ours, have shown that molecular determinants of synaptic plasticity, including brain-derived neurotrophic factor (BDNF), phosphorylation of CREB at Ser133 (pCREB ${ }^{\text {Ser } 133}$ ), calcium-calmodulin kinase II (CaMKII) at Thr286 (pCaMKII ${ }^{\text {Thr } 286}$ ) and AMPA receptor GluA1 subunit at Ser831 (pGluA1 ${ }^{\text {Ser831}}$ ), are engaged and boosted by transcranial direct current stimulation (tDCS) - a noninvasive neuromodulatory technique - resulting in increased LTP and enhanced cognitive or motor functions, depending on the stimulated brain area (Ranieri et al., 2012; Rohan et al., 2015; Podda et al., 2016; Kim et al., 2017; Paciello et al., 2018; Stafford et al., 2018; Barbati et al., 2019; Yu et al., 2019; Kronberg et al., 2020).

We hypothesized that tDCS might differentially impact LTP and memory in $3 \times \mathrm{Tg}-\mathrm{AD}$ mice, a common model of $\mathrm{AD}$, at a stage when the $\mathrm{AD}$ phenotype is not manifested yet (i.e., at 3 months of age, hereinafter referred to as $3 \times \mathrm{Tg}-\mathrm{AD}-3 \mathrm{M}$ mice)
(Oddo et al., 2003; Stover et al., 2015; Belfiore et al., 2019), thus unveiling early dysfunction of synaptic plasticity mechanisms.

We found that tDCS failed to enhance LTP at CA3CA1 synapses and memory in $3 \times \mathrm{Tg}-\mathrm{AD}-3 \mathrm{M}$ mice whereas it increased these parameters in age-matched wild-type (WT) mice. Of note, $3 \times \mathrm{Tg}-\mathrm{AD}-3 \mathrm{M}$ mice did not show increased $\mathrm{pCREB}^{\text {Ser } 133}$, pCaMKII ${ }^{\text {Thr286, }}$, and BDNF following tDCS, suggesting that these molecular changes could serve as novel early biomarkers for $\mathrm{AD}$. Remarkably, BDNF responsiveness to tDCS was assessed in blood samples, providing an easy-to-detect and low-cost biomarker.

\section{MATERIALS AND METHODS}

\section{Animals}

Data of male triple transgenic $\mathrm{AD}(3 \times \mathrm{Tg}-\mathrm{AD})$ mice, harboring the Swedish human APP, presenilin M146V and tauP301L mutations (Oddo et al., 2003) were compared to C57BL/6 wildtype (WT) mice (Li et al., 2018; Chakroborty et al., 2019; Joseph et al., 2019). The colonies were established in-house at the Animal Facility of the Università Cattolica from breeding pairs purchased from the Jackson Laboratory. The study was performed on 3month-old (3M) $3 \times \mathrm{Tg}$-AD and WT mice $(n=78$ and $n=88$, respectively). Seven-month-old (7M) $3 \times \mathrm{Tg}-\mathrm{AD}$ mice and agedmatched WT mice ( $n=21$ each group) were also tested to validate the time course of $\mathrm{AD}$ phenotype in terms of synaptic plasticity and memory impairment in our experimental conditions. The animals were housed under a $12 \mathrm{~h}$ light-dark cycle at a controlled temperature $\left(22-23^{\circ} \mathrm{C}\right)$ and constant humidity $(60-75 \%)$.

\section{Ethics Statement}

All animal procedures were approved by the Ethics Committee of the Catholic University and were fully compliant with guidelines of the Italian Ministry of Health (Legislative Decree No. 26/2014) and European Union (Directive No. 2010/63/UE) legislations on animal research. All efforts were made to minimize the number of animals used and their suffering.

\section{Electrode Implantation and tDCS Protocol}

TDCS over the hippocampus was delivered using a unilateral epicranial electrode arrangement as previously described (Podda et al., 2016; Barbati et al., 2019). The active electrode consisted of a tubular plastic cannula (internal diameter $3.0 \mathrm{~mm}$ ) filled with saline solution $(0.9 \% \mathrm{NaCl})$ just prior to stimulation; the counter electrode was a conventional rubber-plate electrode surrounded by a wet sponge $\left(5.2 \mathrm{~cm}^{2}\right)$ positioned over the ventral thorax. The center of the active electrode was positioned on the skull over the left hippocampal formation $1 \mathrm{~mm}$ posterior and $1 \mathrm{~mm}$ lateral to the bregma (Franklin and Paxinos, 1997). A unilateral arrangement was chosen, as in our previous study, to reduce the electrode contact area and to prevent currents bypassing the two juxtaposed epicranial electrodes, which might occur using a bipolar configuration. Stimulation of the left side was preferred since experimental evidence suggests that long-term 
memory processing are strictly dependent on this hemisphere (Shipton et al., 2014). This electrode montage was previously shown to target the hippocampus causing neurophysiological, behavioral and molecular changes all related to this brain structure. Furthermore, no changes in BDNF levels were detected in non-stimulated areas such as the cerebellum, and tDCS of the motor cortex caused no changes in the hippocampus (see details in Podda et al., 2016). For electrode implant, animals were anesthetized by an intraperitoneal injection of a cocktail with ketamine $(87.5 \mathrm{mg} / \mathrm{Kg})$ and xylazine $(12.5 \mathrm{mg} / \mathrm{Kg})$ and temperature during surgery was maintained at $37^{\circ} \mathrm{C}$. The scalp and underlying tissues were removed and the electrode was implanted using a carboxylate cement (3M ESPE, Durelon, 3M Deutschland GmbH, Germany). All animals were allowed to recover for 3-5 days before tDCS. During this period, as well as during the electrical stimulations, mice were placed in individual cages.

TDCS was applied to awake mice using a battery-driven, constant current stimulator (BrainSTIM, EMS, Italy). The current intensity was ramped for $10 \mathrm{~s}$ instead of switching it on and off to avoid a stimulation break effect.

A repeated tDCS protocol was used consisting in 3 single stimulation sessions (at a current intensity of $250 \mu \mathrm{A}$ for $20 \mathrm{~min}$, current density of $35.4 \mathrm{~A} / \mathrm{m}^{2}$ ) once per day, on 3 consecutive days. According to clinical and brain slice conventions (Jackson et al., 2016; Rahman et al., 2017), we applied "anodal” tDCS corresponding to a positive electric field (positive electrode over the hippocampus). Electrode montage and current density were similar to those recently adopted for rodent models and close to the recommended safety limits in rodents (Rohan et al., 2015; Podda et al., 2016; Jackson et al., 2017; Paciello et al., 2018).

On the 3 consecutive days, tDCS was performed approximately at the same time (around 10 a.m.). No abnormal behaviors were observed related to the stimulation and no morphological alterations were found in brain tissues of mice subjected to tDCS.

Three-month-old WT and $3 \times \mathrm{Tg}-\mathrm{AD}$ mice were randomly assigned to the following experimental groups: (i) sham mice (sham-WT-3M, sham-3×Tg-AD-3M), which underwent the same manipulations as in the "real" stimulation condition, but no current was delivered; (ii) tDCS mice (tDCS-WT-3M, tDCS$3 \times$ Tg-AD-3M), which were subjected to repeated anodal tDCS. Different groups of mice were used for each experimental test.

\section{Electrophysiology}

Field recordings were performed on hippocampal coronal slices (400 $\mu \mathrm{m}$-thick) as previously described (Podda et al., 2008, 2016). Briefly mice were anesthetized by isoflurane inhalation (Esteve) and decapitated. The brain was rapidly removed and placed in ice-cold cutting solution (in mM: $124 \mathrm{NaCl}, 3.2 \mathrm{KCl}, 1 \mathrm{NaH}_{2} \mathrm{PO}_{4}$, $26 \mathrm{NaHCO}_{3}, 2 \mathrm{MgCl}_{2}, 1 \mathrm{CaCl}_{2}, 10$ glucose, 2 sodium pyruvate, and 0.6 ascorbic acid, bubbled with $95 \% \mathrm{O}_{2}-5 \% \mathrm{CO}_{2} ; \mathrm{pH} 7.4$ ). Slices were cut with a vibratome (VT1200S) and incubated in artificial cerebrospinal fluid (aCSF; in mM: $124 \mathrm{NaCl} ; 3.2 \mathrm{KCl} ; 1$ $\mathrm{NaH}_{2} \mathrm{PO}_{4}, 26 \mathrm{NaHCO}_{3}, 1 \mathrm{MgCl}_{2}, 2 \mathrm{CaCl}_{2}, 10$ glucose; $95 \% \mathrm{O}_{2}$ $5 \% \mathrm{CO}_{2} ; \mathrm{pH} 7.4$ ) at $32^{\circ} \mathrm{C}$ for $60 \mathrm{~min}$ and then at RT until use. Slices were prepared $\sim 30 \mathrm{~min}$ after $\mathrm{tDCS}$ or sham stimulation protocol. Slices containing the stimulated hippocampus were used for subsequent analyses.

Slices were transferred to a submerged recording chamber and continuously perfused with aCSF (flow rate: $1.5 \mathrm{ml} / \mathrm{min}$ ). The bath temperature was maintained at $30-32^{\circ} \mathrm{C}$ with an in-line solution heater and temperature controller (TC-344B, Warner Instruments). Identification of slice subfields and electrode positioning were performed with $4 \times$ and $40 \times$ water immersion objectives on an upright microscope (BX5IWI, Olympus) and video observation (C3077-71 CCD camera, Hamamatsu Photonics).

All recordings were made using MultiClamp 700B amplifier (Molecular Devices). Data acquisition and stimulation protocols were performed with the Digidata 1440A Series interface and pClamp 10 software (Molecular Devices). Data were filtered at $1 \mathrm{kHz}$, digitized at $10 \mathrm{kHz}$, and analyzed both online and offline.

Field recordings were made using glass pipettes filled with aCSF (tip resistance 2-5 M 2 ) and placed in the stratum radiatum of the CA1 region. Field excitatory post-synaptic potentials (fEPSPs) were evoked by stimulation of the Schaffer collateral using a concentric bipolar tungsten electrode (FHC) connected to a constant current isolated stimulator (Digitimer Ltd.). The stimulation intensity that produced one-third of the maximal response was used for the test pulses and LTP induction. The fEPSP amplitude was measured from baseline to peak. The slope of the rising phase of the fEPSP was also calculated.

For LTP recordings, stable baseline responses were recorded to test stimulations $(0.05 \mathrm{~Hz}$ for $10 \mathrm{~min})$ and then a high-frequency stimulation (HFS) protocol was delivered (4 trains of 50 stimuli at $100 \mathrm{~Hz}, 500 \mathrm{~ms}$ each, repeated every $20 \mathrm{~s}$ ). Responses to test pulses were recorded every $20 \mathrm{~s}$ for $60 \mathrm{~min}$ to assess LTP. LTP was expressed as the percentage of change in the mean fEPSP slope or peak amplitude normalized to baseline values (i.e., mean values for the last $5 \mathrm{~min}$ of recording before HFS, taken as 100\%). HFSelicited fEPSP changes in both amplitude and slope higher than $15 \%$ of baseline values were subjected to data analysis.

\section{Memory Test}

Object recognition test, also known as novel object recognition (NOR) test and Morris water maze (MWM) test were used to assess non-spatial (i.e., recognition) and spatial memory, respectively. These tests were chosen since they are the most widely used and standardized tests of hippocampal-dependent forms of learning and memory (Vorhees and Williams, 2014; Cohen and Stackman, 2015).

Behavioral tests were carried out from 9 a.m. to 4 p.m. and data were blindly analyzed using an automated video tracking system (Any-Maze).

The NOR protocol lasted 3 consecutive days including a familiarization session, a training session and a test session. On the first day, animals were familiarized for $10 \mathrm{~min}$ to the test arena $(45 \mathrm{~cm} \times 45 \mathrm{~cm})$. On the second day (training session), they were allowed to explore two identical objects placed symmetrically in the arena for $10 \mathrm{~min}$. On the third day (test session), a new object replaced one of the old objects. Animals were allowed to explore for $10 \mathrm{~min}$ and a preference index, calculated as the ratio between time spent exploring the novel object and time spent 
exploring both objects, was used to measure recognition memory (Fusco et al., 2019).

MWM was performed as previously described (Podda et al., 2014, 2016). A circular plastic pool (127 cm in diameter) filled with water colored with nontoxic white paint, to obscure the location of an hidden platform, was used as experimental apparatus. The pool was ideally separated into four equal quadrants (NE, corresponding to the target quadrant, SE, NW, and $\mathrm{SW})$ and the platform $(10 \mathrm{~cm} \times 10 \mathrm{~cm})$ was placed at the center of the target quadrant. Visual cues were placed on the walls around the pool to orient the mice. Animals were trained for 4 days, six times a day and the probe test was administered $24 \mathrm{~h}$ after the last training day. Starting positions were varied daily and latencies to reach the platform were recorded. In the probe test, the platform was removed and time spent in the target quadrant was measured (60 s of test duration).

According to published protocols, the following exclusion criteria were applied: total exploration time $<5 \mathrm{~s}$ in the NOR test and floating behavior during training (i.e., not actively searching for the platform) in the MWM test. No animal met exclusion criteria and all results of behavioral studies were included in data analysis.

\section{Western Immunoblot}

Total proteins were extracted from the stimulated hippocampus of control and tDCS-mice sacrificed $2 \mathrm{~h}$ after stimulation, using ice cold RIPA buffer [Pierce; $50 \mathrm{mM}$ Tris, $150 \mathrm{mM}$ $\mathrm{NaCl}, 1 \mathrm{mM}$ EDTA, 1\% DOC, 1\% Triton X-100, 1\% SDS, and $1 \times$ protease, phosphatase- 1 , and phosphatase- 2 inhibitor cocktails (Sigma)]. Tissues were incubated for $15 \mathrm{~min}$ on ice with occasional vortexing and the lysate was spun down at $22,000 \times \mathrm{g}$ for $15 \mathrm{~min}, 4^{\circ} \mathrm{C}$, and $2 \mu \mathrm{l}$ aliquot of the supernatant was assayed to determine the protein concentration (microBCA kit, Pierce). SDS-PAGE reducing sample buffer was added to the supernatant, and samples were heated to $95^{\circ} \mathrm{C}$ for $5 \mathrm{~min}$. Protein lysates $(40 \mu \mathrm{g})$ were loaded onto $10 \%$ or $8 \%$ Tris-glycine polyacrylamide gels for electrophoretic separation. Precision Plus Protein Dual Color Standards (Bio-Rad) were used as molecular mass standards. Proteins were then transferred onto nitrocellulose membranes at $330 \mathrm{~mA}$ for $2 \mathrm{~h}$ at $4^{\circ} \mathrm{C}$ in transfer buffer containing $25 \mathrm{mM}$ Tris, $192 \mathrm{mM}$ glycine and $20 \%$ methanol. Membranes were incubated for $1 \mathrm{~h}$ with blocking buffer (5\% skim milk in TBST), and then incubated overnight at $4^{\circ} \mathrm{C}$ with primary antibodies directed against one of the following proteins: pCREB $^{\text {Ser133 }}$, CREB, pCaMKII ${ }^{\text {Thr286, }}$ CaMKII, and GAPDH (Supplementary Table 1). After three $10 \mathrm{~min}$ rinses in TBST, membranes were incubated for $2 \mathrm{~h}$ at RT with HRP-conjugated secondary antibodies (Supplementary Table 1). The membranes were then washed, and the bands were visualized with an enhanced chemiluminescence detection kit (GE Healthcare, United Kingdom). Protein expression was evaluated and documented using UVItec Cambridge Alliance. Experiments were performed in triplicate.

\section{ELISA Measurements}

Blood samples were collected from the retro-orbital plexus with sterile glass Pasteur pipettes. Samples were taken before and 1 week after tDCS. After centrifugation, plasma was separated and stored at $-80^{\circ} \mathrm{C}$ until further use. Plasma levels of BDNF were determined using commercially available ELISA kits (Immunological Sciences). The assay was performed according to the manufacturer's instructions on samples collected from 4 animals per group, and each sample was analyzed in duplicate.

\section{Statistical Analysis}

Sample sizes were chosen with adequate statistical power (0.8) according to results of prior pilot data sets or studies, including our own using similar methods or paradigms. Sample estimation and statistical analysis were performed using the SigmaPlot 14.0 software. Data were first tested for equal variance and normality (Shapiro-Wilk test) and then the appropriate statistical tests were chosen. The statistical tests used [i.e., one-way ANOVA, one-way ANOVA for repeated measures (RM), Friedman RM ANOVA on Ranks, two-way ANOVA, two-way RM ANOVA] are indicated in the main text and in the corresponding figure legends for each experiment. Post hoc multiple comparisons were performed with Bonferroni correction. The level of significance was set at 0.05 . Results are presented as mean \pm SEM. Analyses were performed blinded.

\section{RESULTS}

\section{Characterization of Memory and Synaptic Plasticity Impairments in 3xTg-AD Mice}

The objective of the study was to test whether anodal tDCS can be exploited to unmask covert impairment of brain plasticity mechanisms in $3 \times \mathrm{Tg}-\mathrm{AD}$ mice before synaptic plasticity and memory deficits are clearly manifested in this AD mouse model, with the ultimate goal to identify early neurophysiological and molecular biomarkers allowing to predict disease onset.

Our first step was to characterize the time course of the $3 \times \mathrm{Tg}$ $\mathrm{AD}$ mouse phenotype in our experimental conditions, given that some variability has been reported in literature (Belfiore et al., 2019). Specifically, memory and LTP were assessed in 3 and 7 months old AD mice, chosen as putative pre-symptomatic and $\mathrm{AD}$ models, respectively. Different cohorts of mice were used for 3 and 7 months.

Results were compared to those obtained in age-matched WT animals. We found that, at 3 months of age, $3 \times \mathrm{Tg}-\mathrm{AD}$ mice did not exhibit any impairment in recognition and spatial memory, as assessed by NOR and MWM tests, respectively (Figures 1A-C). In particular, in the NOR test the preference index was comparable in $3 \times \mathrm{Tg}-\mathrm{AD}$ and age-matched WT mice $(63.8 \pm 1.7 \%$ and $65.7 \pm 1.7 \%$, respectively, $n=9$ for each group; $P=0.40$, one-way ANOVA; Figure 1A; exploration time: WT$3 \mathrm{M}$ mice, novel object (NO) $11.3 \pm 1 \mathrm{~s}$, familiar object (FO) $5.9 \pm 0.5 \mathrm{~s} ; 3 \times \mathrm{Tg}-\mathrm{AD}-3 \mathrm{M}$ mice, NO $11.5 \pm 2.6 \mathrm{~s}$, FO $6.4 \pm 1.3$ s). Similarly, in the acquisition session of the MWM, all mice successfully acquired the task with latency to reach the platform decreasing progressively across training days [main effect of days: $F_{(3,48)}=34.13, P<0.001$, two-way RM ANOVA] and no 


\section{3 months of age}

A

B

C
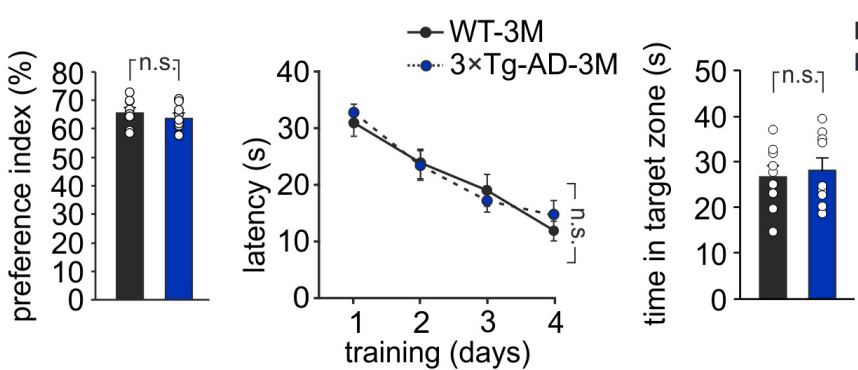

WT-3M

- 3×Tg-AD-3M
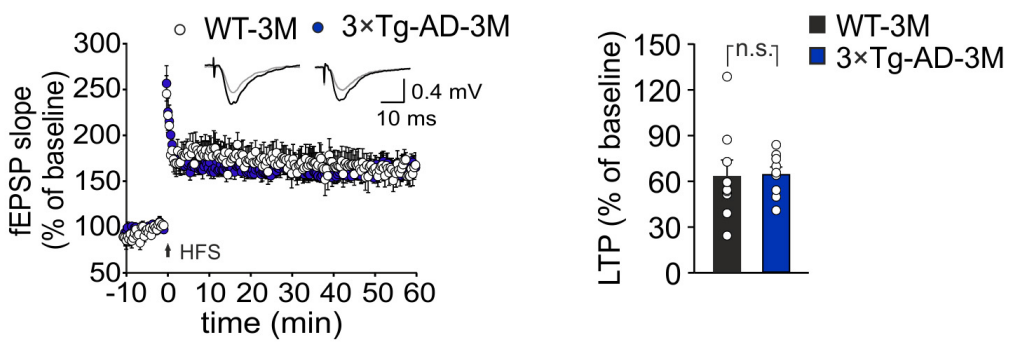

time (min)

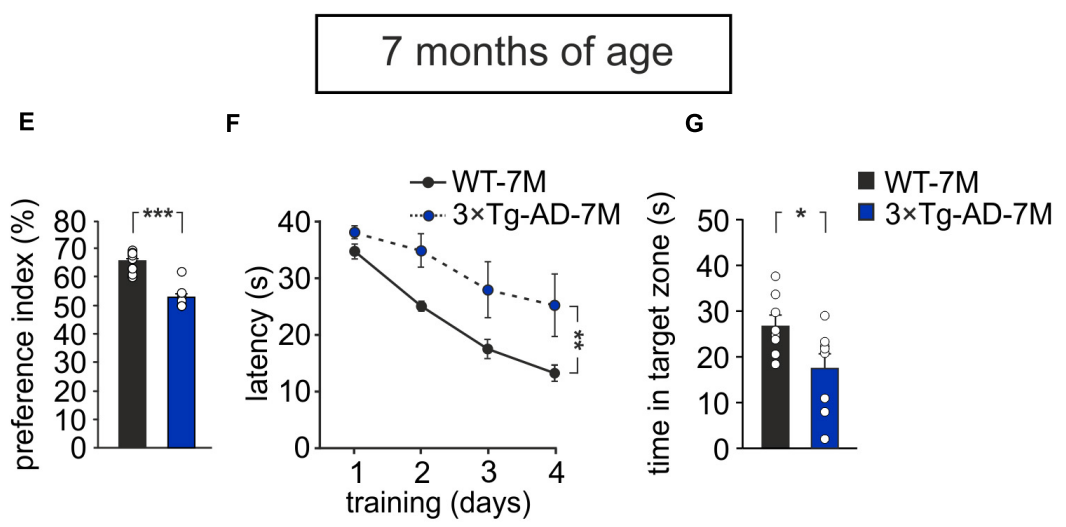

H
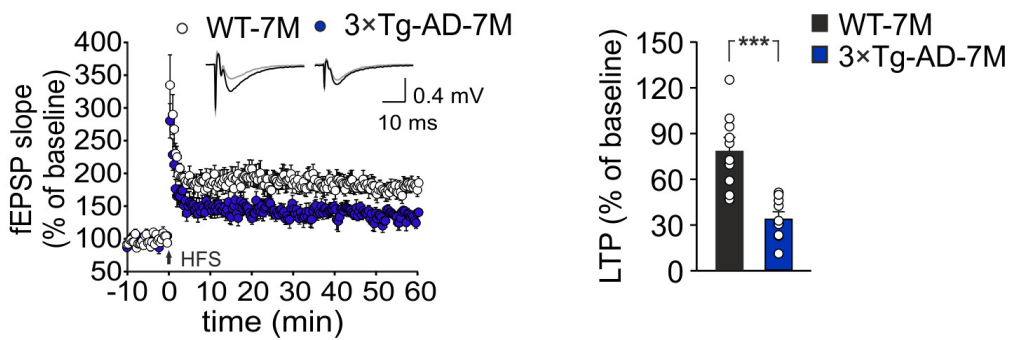

FIGURE 1 | Age-dependent pathological memory and synaptic plasticity changes in 3×Tg-AD mice. (A-D) 3-month-old 3×Tg-AD mice did not differ from age-matched WT mice in: (A) the preference toward the novel object in the NOR test $(n=9$ mice for each group; $P=0.40$, one-way ANOVA); (B) the latency to platform in the training phase of the MWM test $(n=9$ mice for each group; $P=0.73$, two-way RM ANOVA) and (C) the time spent in the target quadrant during the probe test performed on day 5 of MWM ( $P=0.66$, one-way ANOVA); (D) the magnitude of LTP at hippocampal CA3-CA1 synapses $(n=9$ slices from 5 $3 \times$ Tg-AD-3M mice; $n=9$ slices from 6 WT-3M mice; $P=0.89$, one-way ANOVA). Time course shows LTP at CA3-CA1 synapses induced by HFS ( 4 trains of 50 stimuli at $100 \mathrm{~Hz}$ for $500 \mathrm{~ms}$ repeated every $20 \mathrm{~s}$ ) delivered at time 0 (arrow). Results are expressed as percentages of baseline fEPSP slope ( = 100\%). Insets show representative fEPSPs at baseline (gray line) and during the last 5 min of LTP recording (black line). Bar graphs compare LTP observed during the last 5 min of recording. (E-H) Compared to aged-matched WT mice, 7-month-old 3×Tg-AD mice showed significant decreases in: (E) preference index in the NOR test $(P<0.001)$; (F) latency to platform in the training phase of the MWM test $(n=8$ mice for each group; $P=0.009$, two-way RM ANOVA) and (G) time spent in the target quadrant during the probe test of MWM ( $P=0.032$, one-way ANOVA); (H) LTP ( $n=10$ slices from $53 \times$ Tg-AD-7M mice; $n=10$ slices from 5 WT-7M mice, $P=0.0001$, one-way ANOVA). Data are expressed as mean \pm SEM. ${ }^{\star} P<0.05 ;{ }^{\star \star} P<0.01 ;{ }^{\star \star \star} P<0.001$; n.s., not significant. 
significant differences between WT-3M and $3 \times$ Tg-AD-3M mice in all trials ( $n=9$ for each group; $P=0.73$, two-way RM ANOVA; Figure 1B) were noted. In the probe test, the time spent in the target quadrant was similar in $3 \times \mathrm{Tg}-\mathrm{AD}-3 \mathrm{M}$ and WT-3M mice $(28.6 \pm 2.8$ s vs. $27.0 \pm 2.5$ s, respectively, $P=0.66$, one-way ANOVA; Figure 1C). Both groups spent significantly more time in the target quadrant compared to random quadrant occupancy [i.e., $15 \mathrm{~s}$; WT- $3 \mathrm{M}$ mice, $F_{(1,19)}=16.38, P=0.0006 ; 3 \times \mathrm{Tg}$ AD-3M mice, $F_{(1,19)}=18.50, P=0.0003$, one-way ANOVA]. Memory deficits were, instead, manifested in 7-month-old $3 \times \mathrm{Tg}$ $\mathrm{AD}$ mice $(3 \times \mathrm{Tg}-\mathrm{AD}-7 \mathrm{M})$. In the NOR test, they showed a lower preference index than age-matched WT mice $(53.2 \pm 1.5 \%$ vs. $65.6 \pm 1.4 \%$ in WT-7M mice; $n=8$ for each group; $P<0.001$, one-way ANOVA; Figure 1E; exploration time: WT-7M mice, NO $9.2 \pm 1.2$ s, FO $4.9 \pm 0.7$ s; $3 \times$ Tg-AD-7M, NO $6.2 \pm 1.5$ $\mathrm{s}$, FO $5.5 \pm 1.3 \mathrm{~s}$ ). In the acquisition session of the MWM, all mice displayed decreased latency to reach the hidden platform over training days [main effect of days: $F_{(3,42)}=14.72, P<0.001$, two-way RM ANOVA, but $3 \times \mathrm{Tg}-\mathrm{AD}-7 \mathrm{M}$ mice took longer time to find the platform than WT-7M mice $(n=8$ for each group; $P=0.009$, two-way RM ANOVA; Figure 1F). In the probe test, $3 \times \mathrm{Tg}-\mathrm{AD}-7 \mathrm{M}$ mice explored the target quadrant less than controls $(17.4 \pm 3.5 \mathrm{~s}$ vs. $27.0 \pm 2.5 \mathrm{~s}$ in WT-7M mice; $P=0.032$, one-way ANOVA; Figure 1G). Finally, WT-7M mice spent significantly more time in the target quadrant compared to random quadrant occupancy while $3 \times \mathrm{Tg}-\mathrm{AD}-7 \mathrm{M}$ mice failed to do so [WT-7M mice, $F_{(1,18)}=16.17, P=0.0008 ; 3 \times$ Tg-AD-7M mice, $F_{(1,18)}=0.85, P=0.36$, one-way ANOVA].

As expected, behavioral data were paralleled by electrophysiological data showing a significant reduction of LTP at CA3-CA1 hippocampal synapses in brain slices from $3 \times \mathrm{Tg}-\mathrm{AD}-7 \mathrm{M}$ mice $[34.37 \pm 4.36 \%(n=10$ slices from 5 mice $)$ vs. $78.85 \pm 8.09 \%$ ( $n=10$ slices obtained from 5 WT-7M mice); $P=0.0001$, one-way ANOVA; Figure $1 \mathbf{H}]$, whereas LTP was not significantly different in transgenic and WT mice at 3 months of age $[65.11 \pm 4.86 \%$ ( $n=9$ slices from $53 \times$ Tg-AD-3M mice) vs. $63.68 \pm 10.74 \%$ ( $n=9$ slices from $6 \mathrm{WT}-3 \mathrm{M}$ mice); $P=0.89$, one-way ANOVA; Figure 1D]. Data reported above refer to analysis of fEPSP slope. A similar picture emerged when LTP was assessed by analyzing fEPSP amplitude (Supplementary Figures 1A,B). In agreement with our previous result (Leone et al., 2019). Western immunoblot experiments, performed with the $6 \mathrm{E} 10$ antibody recognizing human $\mathrm{A} \beta$, revealed $\mathrm{A} \beta$ oligomers in hippocampal lysates of $3 \times \mathrm{Tg}-\mathrm{AD}-7 \mathrm{M}$ mice (Supplementary Figure 1C). A faint band was observed at the same molecular weight in tissues from $3 \times \mathrm{Tg}-\mathrm{AD}-3 \mathrm{M}$.

Altogether these data indicate that, at 3 months of age, $3 \times \mathrm{Tg}$ $\mathrm{AD}$ mice do not show synaptic plasticity and memory deficits and, therefore, they are a suitable model of a pre-symptomatic $\mathrm{AD}$ stage to test our hypothesis.

\section{Anodal tDCS Fails to Enhance Recognition and Spatial Memory in 3xTg-AD-3M Mice}

We then compared memory performances of $3 \times \mathrm{Tg}-\mathrm{AD}-3 \mathrm{M}$ and age-matched WT mice subjected to a protocol of triple tDCS or sham stimulation. Consistently with our previous findings (Podda et al., 2016), WT mice subjected to tDCS showed a greater preference toward the novel object than sham-stimulated mice [preference index: $70.7 \pm 1.1 \%(n=10)$ and $63.5 \pm 1.8 \%$ $(n=9)$, respectively, $P=0.001$, one-way ANOVA; Figure 2A]. As expected from data reported above, sham-3×Tg-AD-3M mice showed intact recognition memory [preference index: $61.0 \pm 2.1 \%(n=9), P=0.36$ vs. sham-WT-3M mice, one-way ANOVA; Figure 2A]. Of note, preference for the novel object was not increased by tDCS in $3 \times \mathrm{Tg}-\mathrm{AD}-3 \mathrm{M}$ mice [preference index: $64.6 \pm 4.3 \%(n=8), P=0.42$ vs. sham- $3 \times \mathrm{Tg}-\mathrm{AD}-3 \mathrm{M}$ mice $(n=9)$ one-way ANOVA; Figure 2A]. Similar results were obtained with MWM, as shown in Figures 2B,C. In the acquisition session of the MWM, all mice successfully acquired the task with latency to reach the platform decreasing progressively across training days

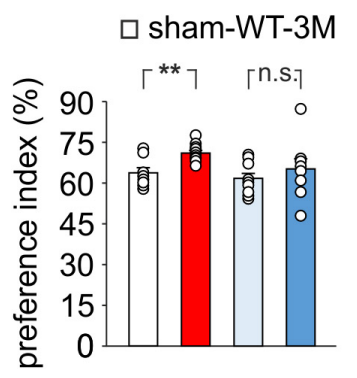

B

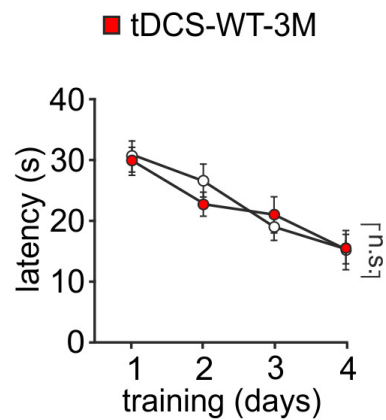

$\square$ sham-3×Tg-AD-3M

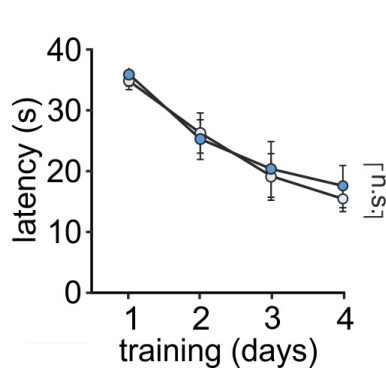

C

$\square$ tDCS-3×Tg-AD-3M

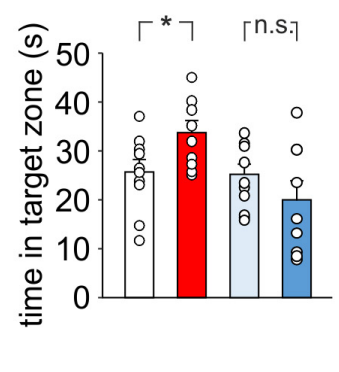

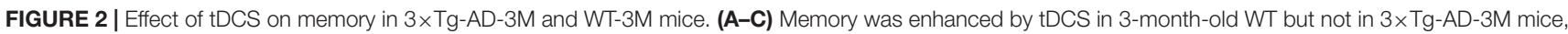
as shown by: (A) preference toward the novel object in NOR test $(n=9$ sham-WT-3M mice vs. $n=10$ tDCS-WT-3M mice, $P=0.001 ; n=9$ sham-3 $\times$ Tg-AD-3M mice vs. $n=8$ tDCS-3 $\times$ Tg-AD-3M mice, $P=0.42$, one-way ANOVA); (B) latency to reach the platform in the training phase of the MWM test ( $n=10$ sham-WT-3M mice and $n=9$ tDCS-WT-3M mice, $P<0.001 ; n=9$ sham- $3 \times$ Tg-AD-3M mice and $n=9$ tDCS-3 $\times$ Tg-AD-3M mice, $P<0.001$, two-way RM ANOVA across training days) and (C) time spent in the target quadrant during probe test (sham-WT-3M mice vs. tDCS-WT-3M mice, $P=0.029$; sham-3 $\times$ Tg-AD-3M mice vs. tDCS-3×Tg-AD-3M mice; $P=0.24$, one-way ANOVA). Data are expressed as mean \pm SEM. ${ }^{\star} P<0.05$; ${ }^{\star \star} P<0.01$; n.s., not significant. 

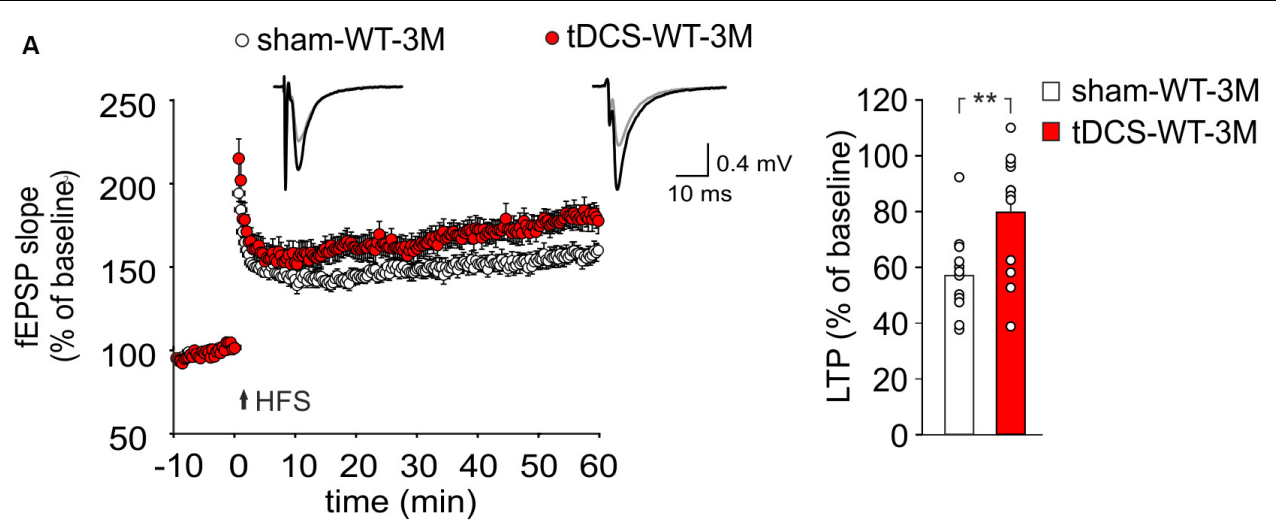

B $\quad$ sham-3×Tg-AD-3M ค tDCS-3×Tg-AD-3M
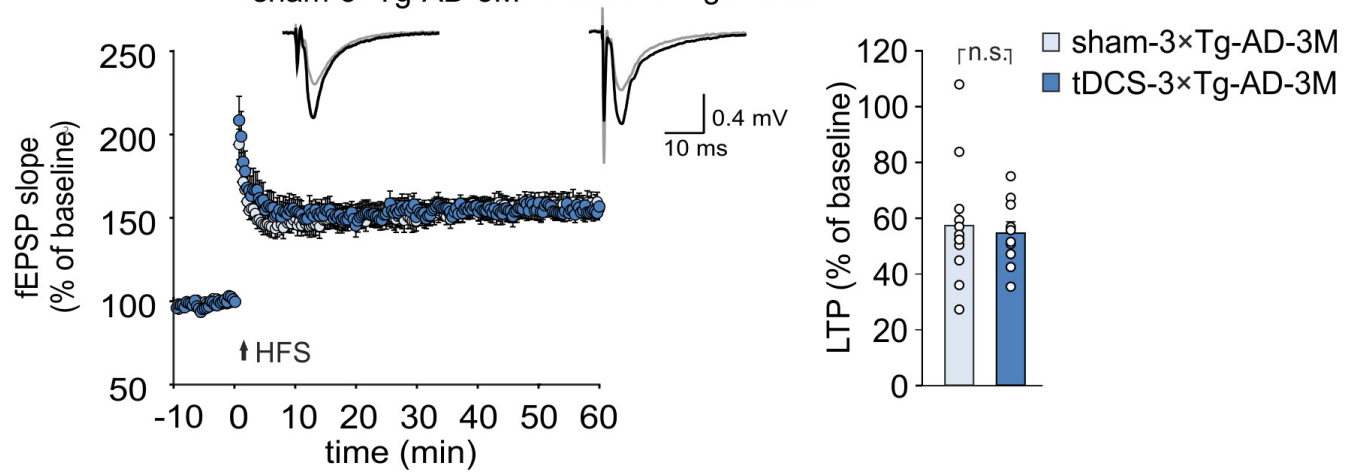

FIGURE 3 | tDCS differentially impacts hippocampal LTP in 3×Tg-AD-3M and WT mice. (A,B) Time course of LTP at CA3-CA1 synapses induced by HFS delivered at time 0 (arrow). Results are expressed as percentages of baseline fEPSP slope ( = 100\%). Insets show representative fEPSPs at baseline ( $g r a y$ line) and during the last 5 min of LTP recording (black line). Bar graphs compare LTP observed during the last 5 min of recording. (A) Slices obtained from tDCS-WT-3M mice $(n=12$ slices from 7 mice) showed enhanced LTP compared to sham-WT-3M mice ( $n=12$ slices from 9 mice, $P=0.007$, one-way ANOVA). (B) tDCS failed to enhance LTP in $3 \times$ Tg-AD-3M mice ( $n=10$ slices from 5 tDCS mice; $n=12$ slices from 5 sham mice, $P=0.71$; one-way ANOVA). Data are expressed as mean \pm SEM;

${ }^{* *} P<0.01$; n.s., not significant.

[WT-3M mice: main effect of days: $F_{(3,51)}=23.85, P<0.001$, two-way RM ANOVA; $3 \times$ Tg-AD-3M mice: main effect of days: $F_{(3,48)}=21.33, P<0.001$, two-way RM ANOVA; Figure 2B], with no significant differences between sham and tDCS in both groups (WT-3M mice: $P=0.81 ; 3 \times$ Tg-AD-3M: $P=0.71$, two-way $\mathrm{RM}$ ANOVA). In the probe test, WT mice, but not $3 \times \mathrm{Tg}-\mathrm{AD}-$ $3 \mathrm{M}$ mice, showed improvement following tDCS [tDCS-WT-3M, $33.5 \pm 2.5 \mathrm{~s}(n=9)$ vs. $25.5 \pm 2.5 \mathrm{~s}(n=10)$ sham-WT-3M; $P=0.029$, one-way ANOVA; tDCS-3 $\times$ Tg-AD-3M, $19.8 \pm 3.9 \mathrm{~s}$ $(n=9)$ vs. $24.9 \pm 2.2 \mathrm{~s}(n=9)$ sham-3 $\times$ Tg-AD-3M; $P=0.24$, one-way ANOVA; Figure 2C).

\section{Anodal tDCS Fails to Enhance LTP in 3xTg-AD-3M Mice}

TDCS effects on memory have been reportedly associated to increased hippocampal LTP (Podda et al., 2016; Yu et al., 2019). We therefore asked whether the behavioral unresponsiveness to tDCS of $3 \times$ Tg-AD-3M mice was associated to the lack of tDCS effects on synaptic plasticity. FEPSP slope was measured in the CA1 area after standard HFS of Schaffer collaterals and LTP was studied in slices from WT and $3 \times \mathrm{Tg}-\mathrm{AD}-3 \mathrm{M}$ mice subjected to tDCS or sham stimulation. Sixty min after HFS, slices from tDCS-WT mice showed significantly greater LTP than slices from sham-WT mice $[79.65 \pm 6.58 \%(n=12$ slices from 7 tDCS mice $)$ vs. $57.0 \pm 4.4 \%$ ( $n=12$ slices from 9 sham mice); $P=0.007$, one-way ANOVA; Figure 3A and Supplementary Figure 2A]. Conversely, LTP was not increased by tDCS in $3 \times$ Tg-AD-3M mice $[54.71 \pm 3.89 \%$ ( $n=10$ slices from 5 tDCS mice) vs. $57.49 \pm 6.23 \%(n=12$ slices from 5 sham mice); $P=0.71$, one-way ANOVA; Figure 3B and Supplementary Figure 2B], demonstrating that in these mice the cellular correlate of memory is also resistant to the boosting action of tDCS.

\section{Molecular Determinants of Plasticity Are Resistant to tDCS Boosting Effects in 3xTg-AD-3M Mice}

The above reported results demonstrate that, before the AD-like phenotype is manifested, $3 \times$ Tg-AD mice - despite normal memory and hippocampal LTP - exhibit decreased responsiveness to the boosting action of tDCS. The reduced response to tDCS might result from initial dysfunction 

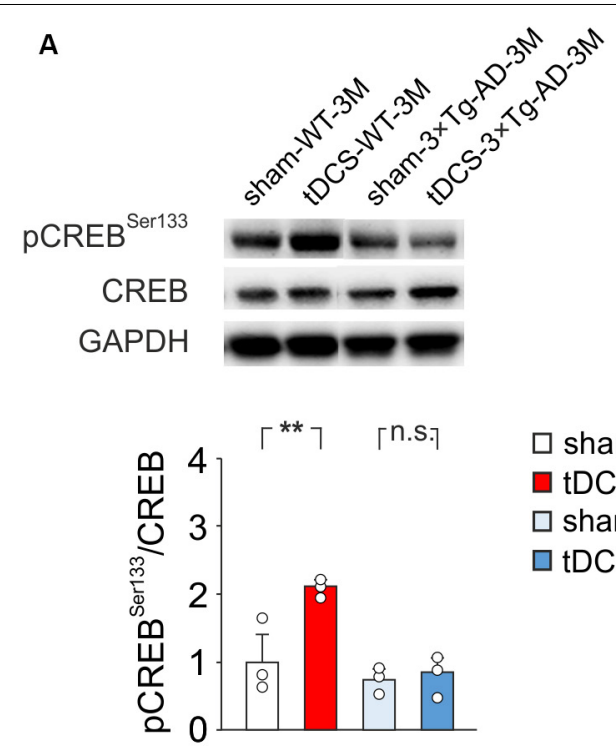

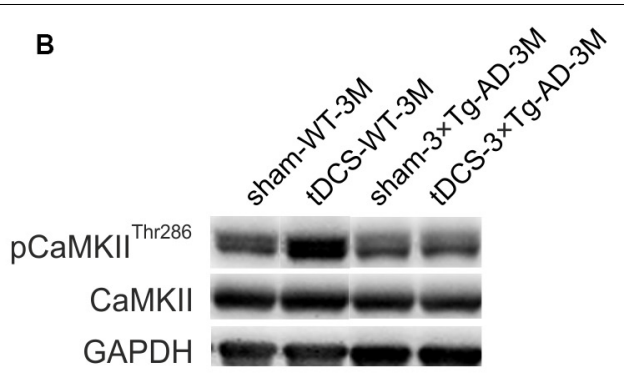

$\square$ sham-WT-3M

IDCS-WT-3M

$\square$ sham-3×Tg-AD-3M

$\square$ tDCS-3×Tg-AD-3M

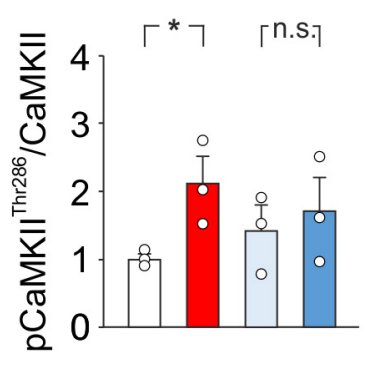

C

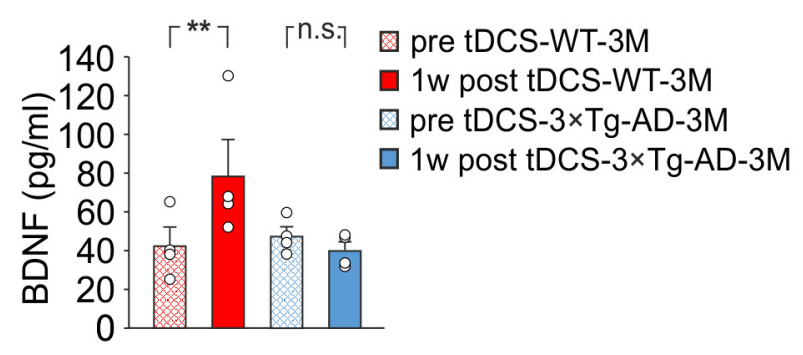

FIGURE 4 | Molecular changes in 3xTg-AD-3M and WT-3M mice following tDCS. Representative immunoblots revealed increased pCREB ${ }^{\text {Ser133 }}$ (A) and pCaMKIITh286 (B) following tDCS in WT-3M mice but not in 3×Tg-AD-3M mice. Bar graphs in the lower panel show results of densitometric analyses on all samples

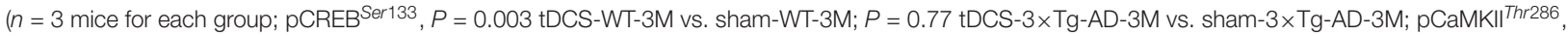
$P=0.045$ tDCS-WT-3M vs. sham-WT-3M; $P=0.58$ tDCS-3 $\times$ Tg-AD-3M vs. sham-3 $\times$ Tg-AD-3M two-way ANOVA, Bonferroni post hoc) normalized to both the corresponding total protein levels and GAPDH. (C) Plasma BDNF levels were measured before (pre) and 1 week after (1 w post) tDCS. BDNF was increased by tDCS in WT mice ( $P=0.031$, one-way RM ANOVA) but not in $3 \times \mathrm{Tg}-\mathrm{AD}-3 \mathrm{M}$ mice $(P=0.12$, Friedman RM ANOVA on Ranks) $(n=4$ mice for each group). Data are expressed as mean \pm SEM. ${ }^{*} P<0.05 ;{ }^{*} P<0.01$; n.s., not significant.

of the molecular pathways underlying plasticity that are challenged by tDCS.

To test this hypothesis, we performed molecular analyses on hippocampi and blood samples from WT and $3 \times$ Tg-AD-3M mice subjected to tDCS or sham stimulation. Our analyses were focused on known upstream mechanisms of tDCS action, such as $\mathrm{Ca}^{2+}$-dependent phosphorylation of CREB at Ser133 and of CaMKII at Thr286, and a pivotal downstream effector, i.e., the neurotrophin BDNF (Podda et al., 2016; Kim et al., 2017; Paciello et al., 2018; Stafford et al., 2018; Barbati et al., 2019).

Our previous observations indicated that tDCS induced CREB activation in the hippocampus $2 \mathrm{~h}$ after stimulation (Podda et al., 2016). Accordingly, immunoblot analyses revealed that, $2 \mathrm{~h}$ after the end of the last tDCS session, hippocampi of WT mice $(n=3)$ showed increased levels of $\mathrm{pCREB}^{\text {Ser } 133}[+110 \%$ vs. sham-WT$3 \mathrm{M}$ mice $(n=3), P=0.003$; two-way ANOVA, Bonferroni post hoc; Figure 4A] and pCaMKII ${ }^{\text {Thr } 286}$ (+109\% vs. sham-WT$3 \mathrm{M}$ mice, $P=0.045$ two-way ANOVA, Bonferroni post hoc;
Figure 4B]. Intriguingly, these post-translational modifications were not observed in $3 \times \mathrm{Tg}-\mathrm{AD}-3 \mathrm{M}$ mice following tDCS $\left(\mathrm{pCREB}^{\text {Ser } 133}\right.$ : $+11 \%$ vs. sham-3 $\times$ Tg-AD-3M mice; $P=0.77$; pCaMKII $^{\text {Thr } 286}:+19 \%$ vs. sham- $3 \times$ Tg-AD-3M mice; $P=0.58$; two-way ANOVA, Bonferroni post hoc; $n=3$ mice each group; Figures 4A,B).

We previously reported that enhanced $\mathrm{pCREB}^{\text {Ser133 following }}$ tDCS increases BNDF expression in the hippocampus by epigenetic regulation of $B d n f$ promoter I (Podda et al., 2016), and similar results were observed in auditory and motor cortices exposed to tDCS (Paciello et al., 2018; Barbati et al., 2019). We, therefore, hypothesized that tDCS could differentially impact BNDF expression in WT-3M and $3 \times \mathrm{Tg}-\mathrm{AD}-3 \mathrm{M}$ mice. Given that changes of brain BDNF expression are reflected in blood (Laske et al., 2006; Brunoni et al., 2015), we asked whether assessment of changes in plasma BDNF following tDCS could be a reliable biomarker of altered brain plasticity in AD. Blood samples used for BDNF testing were collected from each studied 
mice before starting the tDCS and 1 week after the completion of the tDCS protocol. This time point was chosen based on the results of a meta-analysis showing that increased plasma BDNF levels are more frequently observed some days after different protocols of non-invasive brain stimulation (NIBS) than soon after (Brunoni et al., 2015), and our previous studies demonstrated enhanced BDNF expression in the hippocampus 1 week after tDCS (Podda et al., 2016).

Remarkably, we found that plasma BNDF levels were significantly increased after tDCS in WT-3M (78.5 \pm 20.2 vs. $42.3 \pm 9.9 \mathrm{pg} / \mathrm{ml}$ pre-stimulation, $n=4$ mice; $P=0.031$, oneway RM ANOVA) but not in $3 \times$ Tg-AD-3M mice ( $40.1 \pm 4.9$ vs. $47.8 \pm 5.0 \mathrm{pg} / \mathrm{ml}$ pre-stimulation, $n=4$ mice; $P=0.12$, Friedman RM ANOVA on Ranks; Figure 4C).

Our findings indicate that in $3 \times \mathrm{Tg}-\mathrm{AD}-3 \mathrm{M}$ mice molecular determinants of plasticity such as CREB, CaMKII and BDNF are resistant to the boosting effects of tDCS. More importantly, the early impairment of molecular machinery underlying synaptic plasticity and memory in $3 \times \mathrm{Tg}-\mathrm{AD}-3 \mathrm{M}$ mice can be detected by BDNF blood testing following tDCS.

\section{DISCUSSION}

$\mathrm{AD}$ is the most common form of dementia in elderly, characterized by a severe and progressive cognitive decline. So far, no effective treatments have been identified, but accumulating evidence suggests that therapeutics might work best if started at an early disease stage. The preclinical and prodromal phases of $\mathrm{AD}$ are considered promising time-windows for diseasemodifying interventions (Galluzzi et al., 2016; Joe and Ringman, 2019). Therefore, early diagnosis is critical to successfully implement effective treatments.

The diagnosis of preclinical and prodromal AD is presently performed using cerebrospinal fluid analysis, neuroimaging investigations and neuropsychological testing (Lashley et al., 2018). Recently, graph theory analysis of brain connectivity from EEG signals combined with apolipoprotein E genotyping has been proposed to distinguish prodromal to AD from nonprodromal mild cognitive impairment (MCI) subjects (Vecchio et al., 2018). While these diagnostic approaches are valid and reliable, they cannot be employed for a wide ranging screening of persons at risk of $\mathrm{AD}$, because they are invasive, expensive and require equipment and expertise usually only available in specialized hospitals.

Looking for an easy, non-invasive, low-cost and affordable method to screen populations at risk of $\mathrm{AD}$, we investigated brain plasticity responses to tDCS in an AD mouse model before phenotype manifestation. This approach unveiled early electrophysiological and molecular dysfunction leading to the unresponsiveness of $3 \times \mathrm{Tg}-\mathrm{AD}-3 \mathrm{M}$ mice to tDCS boosting effects on memory, LTP and molecular determinants of synaptic plasticity.

Our data suggest that the assessment of plasticity-related molecular biomarkers before and after tDCS could represent a novel approach to predict $\mathrm{AD}$ onset and progression. Of particular relevance for a translational point of view, are the differential effects of tDCS on plasma BDNF levels.

In this study 3 -month-old $3 \times \mathrm{Tg}-\mathrm{AD}$ mice were used as a model of preclinical AD. These mice showed normal memory, as their performance in the NOR and MWM tests was similar to that of age-matched WT mice. At 3 months of age LTP values were also comparable in WT and transgenic mice. Impaired memory and LTP were, instead, observed in AD mice at 7 months of age. Although a certain degree of $3 \times \mathrm{Tg}-\mathrm{AD}$ mouse model heterogeneity has been reported regarding the onset and progression of cognitive deficits, the timeline of the $\mathrm{AD}$ phenotype, in our experimental conditions, is in agreement with literature (Chakroborty et al., 2019; Joseph et al., 2019).

The NIBS techniques have recently gained considerable attention as promising approaches to slow the progression of AD (Rajji, 2019a). Despite encouraging data, conflicting results have been reported so far, likely due to different study designs, patient selection criteria, populations, or sample sizes, therefore, the efficacy of NIBS in AD is still uncertain (Rajji, 2019b). As far as animal models are concerned, tDCS failed to rescue learning and memory deficits in $3 \times \mathrm{Tg}-\mathrm{AD}$ mice when the phenotype is manifested (i.e., $>6$ months of age) (Gondard et al., 2019).

We propose to use tDCS in AD differently, namely, as a tool to probe and challenge plasticity pathways in the presymptomatic phase of the disease in order to unveil their earliest alterations.

Indeed, several studies, including our own, indicated that molecular determinants of plasticity and, particularly, the neurotrophin BDNF, are engaged and boosted by anodal tDCS, leading to enhanced plasticity and memory (Rohan et al., 2015; Podda et al., 2016; Kim et al., 2017; Cocco et al., 2018; Paciello et al., 2018; Stafford et al., 2018; Barbati et al., 2019; Kronberg et al., 2020).

Consistently, we found that 3-month-old WT mice, subjected to a daily session of anodal tDCS for three consecutive days, showed enhanced hippocampus-dependent recognition and spatial memory as assessed by NOR and MWM tests as well as enhanced LTP - the cellular underpinning of memory (Bliss and Collingridge, 1993). Interestingly enough, none of these effects was seen in $3 \times \mathrm{Tg}-\mathrm{AD}-3 \mathrm{M}$ mice.

We, therefore reasoned that the lack of tDCS effects on LTP and memory in $3 \times \mathrm{Tg}-\mathrm{AD}-3 \mathrm{M}$ mice might be due to the unsuccessful recruitment of plasticity-related pathways. We previously identified the signaling cascade engaged by tDCS in the hippocampus, including increased CREB phosphorylation at Ser133 that triggers epigenetic modifications relying on CREB binding to the $B d n f$ promoter $I$ and recruitment of the histone acetyltranferase CREB-binding protein leading to enhanced acetylation at lysine 9 on $B d n f$ promoter $\mathrm{I}$ and increased BDNF expression. Blockade of $\mathrm{H} 3$ acetylation as well as of BDNF-specific TrkB receptors hindered tDCS effects on LTP and memory. Collectively, data summarized above suggested a causal link among the tDCS-induced increases in: (i) CREB phosphorylation; (ii) BDNF expression; (iii) synaptic plasticity; and (iv) memory (Podda et al., 2016). It has also been hypothesized that molecular events underlying tDCS effects are initiated by increased $\mathrm{Ca}^{2+}$ signaling via 
NMDAR and voltage-gated calcium channel activation (Pelletier and Cicchetti, 2014; Rohan et al., 2015). Indeed, $\mathrm{Ca}^{2+}$. dependent intracellular responses observed following tDCS include increased phosphorylation of CREB and CaMKII along with nitric oxide synthase activation (Kim et al., 2017; Cocco et al., 2018; Barbati et al., 2019). In keeping with these data, our Western immunoblot analyses showed enhanced pCREB $^{\text {Ser } 133}$ and pCaMKII ${ }^{T h r 286}$ in tDCS-WT-3M mice. Of relevance, the lack of tDCS effects on LTP and memory in $3 \times$ Tg-AD-3M mice was paralleled by its inability to enhance pCREB $^{\text {Ser133 }}$ and $\mathrm{pCaMKII}{ }^{\mathrm{Th}}{ }^{286}$, indicating that these differential response could serve as novel AD biomarker. Investigating the role of $\mathrm{Ca}^{2+}$ signal dysregulation in the tDCS ineffectiveness on LTP and memory in $3 \times \mathrm{Tg}-\mathrm{AD}-3 \mathrm{M}$ mice was beyond the scope of this research. However, it is worth mentioning that enhanced $\mathrm{Ca}^{2+}$ signaling has been reported in the earliest stages of the disease in mouse AD models (Del Prete et al., 2014; Chakroborty et al., 2019) and it has also been observed in cells from familial AD patients (Nelson et al., 2010). Furthermore, convergent evidence indicates $\mathrm{Ca}^{2+}$ dyshomeostasis within synaptic compartments as an early and critical factor in driving synaptic pathophysiology, leading to cognitive impairment in $\mathrm{AD}$ (Whitcomb et al., 2015).

The main purpose of our study was to identify an early and easy-to-detect $\mathrm{AD}$ biomarker potentially translatable to clinical application. Of course, molecular changes only occurring in the brain would not meet these requirements; therefore, we looked for biomarkers available in the circulating blood. Changes in pCREB and pCaMKII levels in the brain might be paralleled by similar changes in neuron-derived exosomes isolated from circulating blood, which is a promising though still experimental approach (Shi et al., 2016; Badhwar and Haqqani, 2020) we are planning to implement in future studies. Instead, we focused on a much simpler and cheaper approach, based on plasma BDNF level assessment by ELISA (Naegelin et al., 2018), which could be employed in any laboratory performing blood sample testing and therefore, widely accessible to any population. As already mentioned, enhanced BDNF expression in hippocampal lysates was demonstrated in our previous study following tDCS. Although different organs may contribute to determine plasma BDNF levels, several evidences suggest that changes in blood BDNF levels may reflect changes occurring in the brain. Indeed, changes in blood BDNF levels have been associated with a number of neurological diseases including AD (Laske et al., 2006), and they have also been more frequently reported days or weeks after stimulation following tDCS in different clinical conditions or experimental models (Brunoni et al., 2015). $\mathrm{We}$, therefore, compared plasma BDNF levels before and 1 week after tDCS and found that they were significantly increased in $\mathrm{WT}$ but not in $3 \times \mathrm{Tg}-\mathrm{AD}-3 \mathrm{M}$ mice. Investigating the specific contribution of hippocampus vs. other cortical and subcortical areas underneath the stimulating electrode to plasma BDNF levels as well as its different forms (i.e., mature vs. pro-BDNF) was beyond the scope of this paper. Similarly, our study did not address the role of BDNF in AD pathophysiology.
Instead, our novel finding provides a peripheral biomarker of covert neuroplasticity impairment that could be detected in blood samples and easily translated to clinical use. The noninvasiveness and lack of adverse effects of tDCS (Antal et al., 2017) support future longitudinal studies in patient cohorts at risk of $\mathrm{AD}$ including elderly people diagnosed for amnestic MCI or those with genetic risk factors. In summary, our study unravels the unresponsiveness of neuroplasticity mechanisms in the hippocampus to boosting stimuli in a pre-AD stage. The combined use of a non-invasive method such as tDCS and plasma BDNF level assessment before and after treatment appears a novel promising approach to detect synaptic dysfunction far earlier than the appearance of any clinical signs. Although our findings still need to be validated in humans, they indicate a very promising perspective for large population analyses of subjects at risk to develop $\mathrm{AD}$, with far reaching implications for both a personalized approach to $\mathrm{AD}$ patients and public health.

\section{DATA AVAILABILITY STATEMENT}

The raw data supporting the conclusions of this article will be made available by the authors, without undue reservation, to any qualified researcher.

\section{ETHICS STATEMENT}

The animal study was reviewed and approved by the Ethics Committee of the Catholic University and Italian Ministry of Health.

\section{AUTHOR CONTRIBUTIONS}

CG and MP conceived the study and supervised the work. SC, VL, PR, and GA performed the electrophysiological experiments. MR and AM performed the behavioral experiments. SF performed the ELISA experiments. KG and SF performed the WB experiments. DL performed the analysis of $A \beta$ oligomers. MP and CG wrote the manuscript. All authors contributed to the article and approved the submitted version.

\section{FUNDING}

This work was supported by the Italian Ministry of Health Ricerca Finalizzata \# RF-2013-02356444.

\section{SUPPLEMENTARY MATERIAL}

The Supplementary Material for this article can be found online at: https://www.frontiersin.org/articles/10.3389/fcell.2020.00541/ full\#supplementary-material 


\section{REFERENCES}

Antal, A., Alekseichuk, I., Bikson, M., Brockmöller, J., Brunoni, A. R., and Chen, R. (2017). Low intensity transcranial electric stimulation: safety, ethical, legal regulatory and application guidelines. Clin. Neurophysiol. 128, 1774-1809. doi: 10.1016/j.clinph.2017.06.001

Badhwar, A., and Haqqani, A. S. (2020). Biomarker potential of brain-secreted extracellular vesicles in blood in Alzheimer's disease. Alzheimers Dement. 12:e12001. doi: 10.1002/dad2.12001

Barbati, S. A., Cocco, S., Longo, V., Spinelli, M., Gironi, K., Mattera, A., et al. (2019). Enhancing plasticity mechanisms in the mouse motor cortex by anodal transcranial direct-current stimulation: the contribution of nitric oxide signaling. Cereb. Cortex 30, 2972-2985. doi: 10.1093/cercor/bhz288

Bature, F., Guinn, B. A., Pang, D., and Pappas, Y. (2017). Signs and symptoms preceding the diagnosis of Alzheimer's disease: a systematic scoping review of literature from 1937 to 2016. BMJ Open 7:e015746. doi: 10.1136/bmjopen-2016015746

Belfiore, R., Rodin, A., Ferreira, E., Velazquez, R., Branca, C., Caccamo, A., et al. (2019). Temporal and regional progression of Alzheimer's disease-like pathology in 3xTg-AD mice. Aging Cell 18:e12873. doi: 10.1111/acel.12873

Bliss, T. V., and Collingridge, G. L. (1993). A synaptic model of memory: long-term potentiation in the hippocampus. Nature 361, 31-39. doi: 10.1038/361031a0

Bloom, G. S. (2014). Amyloid- $\beta$ and tau: the trigger and bullet in Alzheimer disease pathogenesis. JAMA Neurol. 71, 505-508. doi: 10.1001/jamaneurol.2013.5847

Brunoni, A. R., Baeken, C., Machado-Vieira, R., Gattaz, W. F., and Vanderhasselt, M. A. (2015). BDNF blood levels after non-invasive brain stimulation interventions in major depressive disorder: a systematic review and metaanalysis. World J. Biol. Psychiatry 16, 114-122. doi: 10.3109/15622975.2014. 958101

Chakroborty, S., Hill, E. S., Christian, D. T., Helfrich, R., Riley, S., Schneider, C., et al. (2019). Reduced presynaptic vesicle stores mediate cellular and network plasticity defects in an early-stage mouse model of Alzheimer's disease. Mol. Neurodegener. 14:7. doi: 10.1186/s13024-019-0307-7

Cocco, S., Podda, M. V., and Grassi, C. (2018). Role of BDNF signaling in memory enhancement induced by transcranial direct current stimulation. Front. Neurosci. 12:427. doi: 10.3389/fnins.2018.00427

Cohen, S. J., and Stackman, R. W. Jr. (2015). Assessing rodent hippocampal involvement in the novel object recognition task: a review. Behav. Brain Res. 285, 105-117. doi: 10.1016/j.bbr.2014.08.002

Del Prete, D., Checler, F., and Chami, M. (2014). Ryanodine receptors: physiological function and deregulation in Alzheimer disease. Mol. Neurodegener. 9:21. doi: 10.1186/1750-1326-9-21

Fá, M., Puzzo, D., Piacentini, R., Staniszewski, A., Zhang, H., Baltrons, M. A., et al. (2016). Extracellular tau oligomers produce an immediate impairment of LTP and memory. Sci. Rep. 6:19393. doi: 10.1038/srep19393

Franklin, K. B. J., and Paxinos, G. T. (1997). The Mouse Brain in Stereotaxic Coordinates. New York, NY: Academic Press.

Fusco, S., Spinelli, M., Cocco, S., Ripoli, C., Mastrodonato, A., Natale, F., et al. (2019). Maternal insulin resistance multigenerationally impairs synaptic plasticity and memory via gametic mechanisms. Nat. Commun. 10:4799. doi: 10.1038/s41467-019-12793-3

Galluzzi, S., Marizzoni, M., Babiloni, C., Albani, D., Antelmi, L., Bagnoli, C., et al. (2016). Clinical and biomarker profiling of prodromal Alzheimer's disease in workpackage 5 of the Innovative Medicines Initiative PharmaCog project: a 'European ADNI study'. J. Intern. Med. 279, 576-591. doi: 10.1111/joim.12482

Gondard, E., Soto-Montenegro, M. L., Cassol, A., Lozano, A. M., and Hamani, C. (2019). Transcranial direct current stimulation does not improve memory deficits or alter pathological hallmarks in a rodent model of Alzheimer's disease. J. Psychiatr. Res. 114, 93-98. doi: 10.1016/j.jpsychires.2019.04.016

Gulisano, W., Maugeri, D., Baltrons, M. A., Fà, M., Amato, A., Palmeri, A., et al. (2018a). Role of amyloid- $\beta$ and tau proteins in Alzheimer's disease: confuting the amyloid cascade. J. Alzheimers Dis. 64, S611-S631. doi: 10.3233/JAD179935

Gulisano, W., Melone, M., Li Puma, D. D., Tropea, M. R., Palmeri, A., Arancio, O., et al. (2018b). The effect of amyloid- $\beta$ peptide on synaptic plasticity and memory is influenced by different isoforms, concentrations and aggregation status. Neurobiol. Aging 71, 51-60. doi: 10.1016/j.neurobiolaging.2018.06.025
Irvine, G. B., El-Agnaf, O. M., Shankar, G. M., and Walsh, D. M. (2008). Protein aggregation in the brain: the molecular basis for Alzheimer's and Parkinson's diseases. Mol. Med. 14, 451-464. doi: 10.2119/2007-00100

Jackson, M. P., Rahman, A., Lafon, B., Kronberg, G., Ling, D., Parra, L. C., et al. (2016). Animal models of transcranial direct current stimulation: methods and mechanisms. Clin. Neurophysiol. 127, 3425-3454. doi: 10.1016/j.clinph.2016.08. 016

Jackson, M. P., Truong, D., Brownlow, M. L., Wagner, J. A., McKinley, R. A., Bikson, M., et al. (2017). Safety parameter considerations of anodal transcranial direct current stimulation in rats. Brain Behav. Immun. 64, 152-161. doi: 10. 1016/j.bbi.2017.04.008

Joe, E., and Ringman, J. M. (2019). Cognitive symptoms of Alzheimer's disease: clinical management and prevention. BMJ 367:16217. doi: 10.1136/bmj.16217

Joseph, D. J., Liu, C., Peng, J., Liang, G., and Wei, H. (2019). Isoflurane mediated neuropathological and cognitive impairments in the triple transgenic Alzheimer's mouse model are associated with hippocampal synaptic deficits in an age-dependent manner. PLoS One 14:e0223509. doi: 10.1371/journal.pone. 0223509

Kim, M. S., Koo, H., Han, S. W., Paulus, W., Nitsche, M. A., Kim, Y. H., et al. (2017). Repeated anodal transcranial direct current stimulation induces neural plasticity-associated gene expression in the rat cortex and hippocampus. Restor. Neurol. Neurosci. 35, 137-146. doi: 10.3233/RNN-160689

Kopeikina, K. J., Hyman, B. T., and Spires-Jones, T. L. (2012). Soluble forms of tau are toxic in Alzheimer's disease. Transl Neurosci. 3, 223-233. doi: 10.2478/ s13380-012-0032-y

Kronberg, G., Rahman, A., Sharma, M., Bikson, M., and Parra, L. C. (2020). Direct current stimulation boosts hebbian plasticity in vitro. Brain Stimul. 13, 287-301. doi: 10.1016/j.brs.2019.10.014

Lashley, T., Schott, J. M., Weston, P., Murray, C. E., Wellington, H., Keshavan, A., et al. (2018). Molecular biomarkers of Alzheimer's disease: progress and prospects. Dis. Model. Mech. 11:dmm031781. doi: 10.1242/dmm.031781

Laske, C., Stransky, E., Leyhe, T., Eschweiler, G. W., Wittorf, A., Richartz, E., et al. (2006). Stage-dependent BDNF serum concentrations in Alzheimer's disease. J. Neural Transm. 113, 1217-1224. doi: 10.1007/s00702-005-0397-y

Leone, L., Colussi, C., Gironi, K., Longo, V., Fusco, S., Li Puma, D. D., et al. (2019). Altered Nup153 expression impairs the function of cultured hippocampal neural stem cells isolated from a mouse model of Alzheimer's disease. Mol. Neurobiol. 56, 5934-5949. doi: 10.1007/s12035-018-1466-1

Li, T., Jiao, J. J., Hölscher, C., Wu, M. N., Zhang, J., Tong, J. Q., et al. (2018). A novel GLP-1/GIP/Gcg triagonist reduces cognitive deficits and pathology in the 3xTg mouse model of Alzheimer's disease. Hippocampus 28, 358-372. doi: 10.1002/hipo.22837

Merlo, S., Spampinato, S. F., and Sortino, M. A. (2019). Early compensatory responses against neuronal injury: a new therapeutic window of opportunity for Alzheimer's disease? CNS Neurosci. Ther. 25, 5-13. doi: 10.1111/cns. 13050

Naegelin, Y., Dingsdale, H., Säuberli, K., Schädelin, S., Kappos, L., and Barde, Y. A. (2018). Measuring and validating the levels of brain-derived neurotrophic factor in human serum. eNeuro 5:ENEURO.0419-17.2018. doi: 10.1523/ ENEURO.0419-17.2018

Nelson, O., Supnet, C., Liu, H., and Bezprozvanny, I. (2010). Familial Alzheimer's disease mutations in presenilins: effects on endoplasmic reticulum calcium homeostasis and correlation with clinical phenotypes. J. Alzheimers Dis. 21, 781-793. doi: 10.3233/JAD-2010-100159

Oddo, S., Caccamo, A., Shepherd, J. D., Murphy, M. P., Golde, T. E., Kayed, R., et al. (2003). Triple-transgenic model of Alzheimer's disease with plaques and tangles: intracellular A $\beta$ and synaptic dysfunction. Neuron 39, 409-421. doi: 10.1016/S0896-6273(03)00434-3

Paciello, F., Podda, M. V., Rolesi, R., Cocco, S., Petrosini, L., Troiani, D., et al. (2018). Anodal transcranial direct current stimulation affects auditory cortex plasticity in normal-hearing and noise-exposed rats. Brain Stimul. 11, 10081023. doi: 10.1016/j.brs.2018.05.017

Pelletier, S. J., and Cicchetti, F. (2014). Cellular and molecular mechanisms of action of transcranial direct current stimulation: evidence from in vitro and in vivo models. Int. J. Neuropsychopharmacol. 18:yu047. doi: 10.1093/ijnp/ pyu047

Podda, M. V., Cocco, S., Mastrodonato, A., Fusco, S., Leone, L., Barbati, S. A., et al. (2016). Anodal transcranial direct current stimulation boosts synaptic plasticity 
and memory in mice via epigenetic regulation of Bdnf expression. Sci. Rep. 6:22180. doi: $10.1038 /$ srep 22180

Podda, M. V., D’Ascenzo, M., Leone, L., Piacentini, R., Azzena, G. B., and Grassi, C. (2008). Functional role of cyclic nucleotide-gated channels in rat medial vestibular nucleus neurons. J. Physiol. 586, 803-815. doi: 10.1113/jphysiol.2007. 146019

Podda, M. V., Leone, L., Barbati, S. A., Mastrodonato, A., Li Puma, D. D., and Piacentini, R. (2014). Extremely low-frequency electromagnetic fields enhance the survival of newborn neurons in the mouse hippocampus. Eur. J. Neurosci. 39, 893-903. doi: 10.1111/ejn.12465

Puzzo, D., Piacentini, R., Fà, M., Gulisano, W., Li Puma, D. D., Staniszewski, A., et al. (2017). LTP and memory impairment caused by extracellular A $\beta$ and Tau oligomers is APP-dependent. eLife 6:e26991. doi: 10.7554/eLife.26991

Rahman, A., Lafon, B., Parra, L. C., and Bikson, M. (2017). Direct current stimulation boosts synaptic gain and cooperativity in vitro. J. Physiol. 595, 3535-3547. doi: 10.1113/JP273005

Rajji, T. K. (2019a). Impaired brain plasticity as a potential therapeutic target for treatment and prevention of dementia. Expert. Opin. Ther. Targets 23, 21-28. doi: 10.1080/14728222.2019.1550074

Rajji, T. K. (2019b). Transcranial magnetic and electrical stimulation in alzheimer's disease and mild cognitive impairment: a review of randomized controlled trials. Clin. Pharmacol. Ther. 106, 776-780. doi: 10.1002/cpt.1574

Ranieri, F., Podda, M. V., Riccardi, E., Frisullo, G., Dileone, M., and Profice, P. (2012). Modulation of LTP at rat hippocampal CA3-CA1 synapses by direct current stimulation. J. Neurophysiol. 107, 1868-1880. doi: 10.1152/jn.00319. 2011

Ripoli, C., Cocco, S., Li Puma, D. D., Piacentini, R., Mastrodonato, A., Scala, F., et al. (2014). Intracellular accumulation of amyloid- $\beta(A \beta)$ protein plays a major role in $\mathrm{A} \beta$-induced alterations of glutamatergic synaptic transmission and plasticity. J. Neurosci. 34, 12893-12903. doi: 10.1523/jneurosci.1201-14.2014

Rohan, J. G., Carhuatanta, K. A., McInturf, S. M., Miklasevich, M. K., and Jankord, R. (2015). Modulating hippocampal plasticity with in vivo brain stimulation. J. Neurosci. 35, 12824-12832. doi: 10.1523/JNEUROSCI.2376-15.2015

Serrano-Pozo, A., Frosch, M. P., Masliah, E., and Hyman, B. T. (2011). Neuropathological alterations in Alzheimer disease. Cold Spring Harb. Perspect. Med. 1:a006189. doi: 10.1101/cshperspect.a006189

Shi, M., Kovac, A., Korff, A., Cook, T. J., Ginghina, C., Bullock, K. M., et al. (2016). CNS tau efflux via exosomes is likely increased in Parkinson's disease but not in Alzheimer's disease. Alzheimers Dement. 12, 1125-1131. doi: 10.1016/j.jalz. 2016.04.003
Shipton, O. A., El-Gaby, M., Apergis-Schoute, J., Deisseroth, K., Bannerman, D. M., Paulsen, O., et al. (2014). Left-right dissociation of hippocampal memory processes in mice. Proc. Natl. Acad. Sci. U.S.A. 111, 15238-15243. doi: 10.1073/ pnas. 1405648111

Stafford, J., Brownlow, M. L., Qualley, A., and Jankord, R. (2018). AMPA receptor translocation and phosphorylation are induced by transcranial direct current stimulation in rats. Neurobiol. Learn. Mem. 150, 36-41. doi: 10.1016/j.nlm.2017. 11.002

Stover, K. R., Campbell, M. A., Van Winssen, C. M., and Brown, R. E. (2015). Early detection of cognitive deficits in the 3xTg-AD mouse model of Alzheimer's disease. Behav. Brain Res. 289, 29-38. doi: 10.1016/j.bbr.2015. 04.012

Vecchio, F., Miraglia, F., Iberite, F., Lacidogna, G., Guglielmi, V., Marra, C., et al. (2018). Sustainable method for Alzheimer dementia prediction in mild cognitive impairment: electroencephalographic connectivity and graph theory combined with apolipoprotein E. Ann. Neurol. 84, 302-314. doi: 10.1002/ana. 25289

Vorhees, C. V., and Williams, M. T. (2014). Assessing spatial learning and memory in rodents. ILAR J. 55, 310-332. doi: 10.1093/ilar/ ilu013

Whitcomb, D. J., Hogg, E. L., Regan, P., Piers, T., Narayan, P., Whitehead, G., et al. (2015). Intracellular oligomeric amyloid-beta rapidly regulates GluA1 subunit of AMPA receptor in the hippocampus. Sci. Rep. 9:10934. doi: 10.1038/ srep10934

Yu, T. H., Wu, Y. J., Chien, M. E., and Hsu, K. S. (2019). Transcranial direct current stimulation induces hippocampal metaplasticity mediated by brainderived neurotrophic factor. Neuropharmacology 144, 358-367. doi: 10.1016/ j.neuropharm.2018.11.012

Conflict of Interest: The authors declare that the research was conducted in the absence of any commercial or financial relationships that could be construed as a potential conflict of interest.

Copyright (C) 2020 Cocco, Rinaudo, Fusco, Longo, Gironi, Renna, Aceto, Mastrodonato, Li Puma, Podda and Grassi. This is an open-access article distributed under the terms of the Creative Commons Attribution License (CC BY). The use, distribution or reproduction in other forums is permitted, provided the original author(s) and the copyright owner(s) are credited and that the original publication in this journal is cited, in accordance with accepted academic practice. No use, distribution or reproduction is permitted which does not comply with these terms. 